\title{
What Do Car Horns Say? An Overview of the Non-Verbal Communication of Horn Honking
}

\author{
Jathla A. Mahmood \\ Department of English, Al Iraqia University, Baghdad, Iraq \\ Email: jathla.ahmed@gmail.com
}

How to cite this paper: Mahmood, J. A. (2021). What Do Car Horns Say? An Overview of the Non-Verbal Communication of Horn Honking. Open Journal of Social Sciences, 9, 375-388.

https://doi.org/10.4236/jss.2021.98026

Received: July 16, 2021

Accepted: August 23, 2021

Published: August 26, 2021

Copyright (อ 2021 by author(s) and Scientific Research Publishing Inc. This work is licensed under the Creative Commons Attribution International License (CC BY 4.0).

http://creativecommons.org/licenses/by/4.0/ (c) (i) Open Access

\begin{abstract}
The current study aims at shedding light on horn honking as an effective channel of non-verbal communication that expresses far more meanings than just aggression and road-related messages. An overview of the use of horn honking in ten different countries is given. The overview shows that horn honking has indeed proven itself as cultural phenomenon essential in the daily lives of many people. The car horn is much more than a mere tool of warning for danger or complaining about some wrong. Many drivers use horn honking as a language, Morse codes, or a medium of communication to express a variety of meanings some of which reinforce social relationships. The overview is discussed from a cultural point of view. A recommendation for more attention to this neglected channel has been made. It needs to be listed as a channel of non-verbal communication or at least be considered as a sub channel of the physical environment.
\end{abstract}

\section{Keywords}

Car Horns, Channels, Communication, Culture, Horn Honking,

Non-Verbal

\section{Introduction}

Communication, as a scientific field of study, is so pervasively important in all walks of our life that many different disciplines such as anthropology, psychology, political sciences, philosophy, linguistics and even medicine are interested in it, study it, and add to our general knowledge about it. It is a social process that humans are noteworthy of. We, humans, spend most of our time in contact with others whether through face to face activities or through cell phones and social networking sites. Thus, communication "performs a bridging function in society" where "our ability to navigate the waters of daily living-indeed, our pros- 
pects for happy, healthy lives-depends on how well we communicate" (Andersen, 2008; Burgoon, Guerrero, \& Floyd, 2016: p. 1; Gozalova, Gazilov, Kobeleva, Seredina, \& Loseva, 2016: p. 553; Miller, 1963). Littlejohn and Foss (2008) and Trenholm and Jensen (cited in Laitinen, 2011) even describe communication as an ongoing, very collective activity completely intertwined with all human life that a human society could not exist without. Here, some may think of the words and sentences we use, but this is not the only way in which human beings communicate. In fact, most messages are communicated beyond the use of language. Communication has both verbal and non-verbal aspects to it (Andersen, 2008; Uyanne \& Oti, 2012). For the current paper, only non-verbal communication is of concern; more specifically, its channels.

\section{Non-Verbal Communication}

While verbal communication often refers to communicating meaning through the use of words, non-verbal communication refers to "all phenomena with a communicative value that are not part of verbal communication" (Surkamp, 2014: p.14). It is a process of generating meaning using some means or behaviors other than spoken or written words (Burgoon \& Hoobler, 2002; Communication in the Real World, 2016; De Vito, 1989; Knapp, Hall, \& Horgan, 2014; Morreale, Spitzberg, \& Barge, 2007; Tripathy, 2017). Or, as is simply stated by Greene, nonverbal communication is "everything we do except the words that we use" (cited in Burgoon et al.: 2016, p.11). This means that we communicate a variety of messages non-verbally when we widen our eyes, smile, frown, gesture, touch or move closer to someone, wear certain things, or raise our voices. Even silence is considered communication when someone attributes meaning to it (De Vito, 2002). These different things we do are known as the channels or codes of nonverbal communication.

As powerful and pervasive as non-verbal form of communication is, it could still be more ambiguous because of the variety of channels it is signaled and interpreted through (Andersen, 2008, 2012). Generally, non-verbal communication channels are divided into two categories; vocal or paralinguistic channels and non-vocal channels. Below is a very short; yet, comprehensive and concise list of these channels as is stated and explained by Andersen $(2008,2009,2012)$; Argyle (2007); Bruneau (2009); Burgoon and Hoobler (2002); Burgoon et al. (2016); Communication in the Real World (2016); De Vito (1989, 2002); Giri (2009); Hall (1959, 1990); Hargie (2006); Knapp et al. (2014); Morreale et al. (2007); Padula (2009a, 2009b); Surkamp (2014) and Ting-Toomy (1999).

1) Vocal/paralinguistic channels (also known as vocalics, prosody or paralanguage).

2) Non-vocal channels. They include:

a) Kinesics, or body language.

b) Haptics.

c) Proxemics.

d) Chronemics. 
e) Physical reactions, outward appearance and olfactics.

f) Physical environment, artifacts or objectics.

Given the list above, no study, to the best knowledge of the researcher, has ever listed car horns as another important channel of non-verbal communication. In many countries, horn honking is not just "rarely" used to communicate roadrelated messages. On the contrary, it is used more frequently to express a variety of meanings; some of which may have a rather more cultural aspect to them, which is the focus of the current study and the motivation behind conducting it. The hypotheses suggested here is that "in many countries, horn honking is a cultural phenomenon that communicates much more than road-related meanings and therefore should be listed as another channel of non-verbal communication".

\section{An Overview of the Non-Verbal Communication of Horn Honking}

Horn honking has been studied by many researchers but mainly in the form of aggression or road rage and factors affecting it such as age, gender, race, status, stress, frustration, traffic and even ambient temperature ${ }^{1}$. Therefore, due to the lack of scientific resources on the topic as a cultural phenomenon, information about horn honking in the different countries mentioned in this section is mostly taken from experiences found in blogs, reports and articles over the web in addition to the author's own experience in her country. In other words, the selection of the countries listed below is based on the availability of data.

In his note on a report about horn honking in Cairo, Cox (2012) wrote:

In Boston, where I live, honking is not considered a skill, and the car horn isn't much of a tool. Hitting the horn is a way of giving obnoxious voice to your frustration at the rest of the world as represented by the idiot who just cut you off.

Another experience about the US is that of N. Miller (2015). He talks about how rarely horn honking is heard because it means "only one of two things. 1) I am six inches away from hitting your car, or 2) Hello, I know you” (para. 2). Martin (2017) and Runn (2011) have a similar view. They argue that Americans use their horns to warn for danger or complain about some wrong; someone's bad driving or breaking the law. Runn (2011) even goes into saying, unlike Italy and India, "we are not a culture that regularly communicates through our car horns" (para. 2). Actually, "in Western cultures the horn is generally associated with road rage and impatience" (Cheuk, 2014, para. 2). This association of horn honking with aggression is documented, as is mentioned earlier, by many researchers in as early as the 1960's (see the Appendix). However, in many other countries, honks express different meanings (Stanciu, Eby, Molnar, Louis, \& Zanier, 2017; Takada, Fukuda \& Iwamiya, 2008) as Martin (2017) advises in his ${ }^{1}$ Because the focus of the current study is on the cultural side of horn honking, these studies are not mentioned in the literature review. Instead, some are listed in the Appendix as further readings on horn honking. 
opening sentence "Tourist drivers, be aware, honking does not mean the same thing all over the globe".

\subsection{In Italy}

After his five-year stay in Italy, Runn (2011) gives us his account of the Italians. He talks about how unsettling it was at first to constantly hear horn honking, and how the Italians love their cars and their car horns. For them, horn honking is used as a regular means of communication. He describes them as "very passionate people"; therefore, "their communication is passionate as well" (para. 3). They use their horns to express their "in the moment" feelings without intending anything negative. Unless one understands this "opera of horns" as described by Martin (2017, para. 8), s/he may think of the Italians as simply rude.

\subsection{In Barbados}

"What's with Barbados drivers and their horns?" A question raised by Shattuck (2009). Walking down the street with a Bajan friend, she narrates when a man walking ahead of them yelled a greeting and waved in response to a car horn. The man knew it was for him and responded as if the horn was a statement, not a sound. Her Bajan friend clarifies saying "when Bajans are behind the wheel of a car, they don't just drive, they talk. In honks" (para. 4). Shattuck describes their honking as friendly, with warmth, and musical that doesn't even have a "honk" sound. It is a personal form of communication with which one can communicate "Hello, I know you and I acknowledge you", "devil-may-car driving style", "flirt with women" and even "Yankee Doodle Dandy". She adds that responding to these musical horns reinforces social relationships while ignoring them can be taken as a snub and the honkee may not be invited to the honker's Christmas party!

\subsection{In Haiti}

In her morning report about the language of car horns in Port-Au-Prince, Hersher (2017) talked about the different meanings of horn honking there. Going on a tour with Paultre; a professional driver, they introduced some of these meanings. Those meanings ranged from road-related like "move ..." or "pay attention" to things like "hello", "thanks", "stop chatting in the middle of the street" and "my truck's brakes don't work that well and I'm coming down the hill anyway ..." According to her, the gridlock at Port-Au-Prince feels lawless; thus, "if you're going to drive, you need to know what the different horns mean."

\subsection{In Jamaica}

The Other Language of Jamaica (2016) is the constant honking of car horns. Driving there can sometimes be as scary as a roller coaster ride at Disneyland. For anyone to feel safe when driving in Jamaican streets, we need to decode 
that language of honks. A very short not loud gentle "beep beep" means "be aware" or "I am overtaking/passing you". A "hoot" is another short friendly horn that is used as a "greeting". A third type of horn is the "toot, toot, toot" which is long and loud but not angry or confrontational. It is just used as "Hey! Whatcha doing" when someone is doing something stupid like socializing instead of driving on the correct side. There is also a loud "honk" that warns other drivers when approaching a blind curve, "AAht AAht BLOOOP" which is definitely a sound of annoyance over someone's bad driving, and finally the "WAAAAAAAAANK". "There's no doubt what this sound is. In any language, the horn blower is telling you to stuff yourself where the sun doesn't shine!" (para. 10).

\subsection{In Canada}

Kelly's (2015) interview with Bob Crisp from the Canadian Motor Vehicles Advisory Commission reveals that the Commission is establishing a new language using distinct horn honking patterns. For effective communication while driving, Crisp and his team have developed a system of fifty-four different horns that can communicate almost everything like a Morse code. Some of the meanings to be communicated are "Move over", "my right of way", "be wary construction ahead”, "nice wheels!", "flat tire”, "you could use a carwash", "children at play", "pleasant greetings", "happy holidays" and even "congratulations on your honor, student". The system was to be applied for trial all across Canada in early 2016. Kelly states that finally the "Canadians will have a solution to the aged old problem of how to communicate effectively using their car horn."

\subsection{In Thailand}

In Thailand where the streets are full of taxis and tuk-tuks, the sharp horns are more friendly. Those many horns one hears have meanings like "Hi, how are ya? I'm here.", "Please keep your motorbike no more than one centimeter away from my bumper at all times.", or even something like "How do you balance all those chicken coops without a trailer?" Those afraid of getting a few horns may not be able to survive two minutes on the road except if they "proceed with caution" and "embrace the toot toot" (Martin, 2017, para. 4).

\subsection{In China}

"It seems that horn honking in China is not just noise at all, but in fact serves, in many cases, as a sort of medium of communication between drivers and pedestrians" (Cheuk, 2014, para. 2). Just as the Chinese language has tones, their car horns do as well. Depending on the situation, various types of honks (lengths, intensities, loudness) are heard in the streets and each delivers a certain message. For example; a short quick horn may mean "Hey, I'm here, watch out!" or "Why aren't you moving, the light just changed?" whereas a very short almost polite one means "Hey I'm a taxi, need a ride?" A prolonged ear-piercing horn, which 
is usually a technique used by bus drivers, is perceived as angry or impatient gesture that means "Why are you not moving? Are you deaf? Can't you hear the honking that I've been doing for one minute now?" A fourth type is a short but angry horn which says "You just cut me off! What's your problem!?" Driving in China is interesting; it can be described as an "organized chaos" where everybody understands and accepts their culture of horns as part of their daily life (Blinkhorn, 2013; Cheuk, 2014).

\subsection{In India}

In India, horns are more loquacious. They are as important as, if not more important than, the brakes (Miller, 2015; Rapoza, 2014). N. Miller gives a pretty long list of horn honking patterns; the single, the double, the triple, the repeated triple, the big blast, etc. and their meanings. Some of these meanings are "I am here", "please don't be dumb ...", "I am upset that traffic has not moved ...", “I am more important than you; get out of my way", "I am literally about to hit you", and for large vehicles a honk means "I can do whatever I want because I am massive". Car horns are so many in India that Runn (2011) calls it a "horn honking culture" where he has never heard as many horns in his life. He explains that for a foreign passenger, the experience can be "frightening" and "confusing" unless s/he knows that those skilled drivers are not angry, annoyed, or informing about some law that has been broken. They are merely communicating using their horns, or as he describes it: "using the skiing etiquette". Rapoza (2014) states that "perhaps the most unique cultural takeaway from India ... is the car horn. Indians honk like nobody's business" (para. 1).

\subsection{In Egypt}

Having lived in Cairo for over two years, Simon (2012) reports that "whenever I'd walk down the street and hear a honk that I thought was just a ... honk. It turns out, that honk has a meaning" (para. 1). Cox (2012) reports that in Cairo and many other cities drivers are more expressive, creative and noisier. Many of them put in a louder horn when they get a new car. According to several taxi and microbus drivers there, "honking is a language". To make words, like Morse code, drivers mix short and long honks. These mixed honks will have meanings like "open your eyes", "let me pass", "what's taking you so long?", "thanks", "I’m just here to annoy everyone", "some descriptive swearwords", "insults", "anger", "I love you", "hello beautiful!" or even "here comes the bride!". And, as can be seen from these meanings, honks are not just for fellow drivers. They are for those walking down the streets as well (Kamel, 2015; Scoop Team 2017; Simon, 2012). Simon also adds that not everyone may know the meanings of these honks as they may sound similar to the untrained ear in addition to being "a male language."

\footnotetext{
2"Skiing etiquette dictates that you let the skier in front of you know that you are about to pass them on the hill and to let them know which side you are on.” (Runn, 2011, para. 4).
} 


\subsection{In Iraq}

Having been to Iraq myself, there are not as many horns as those in other countries mentioned above. Yet, Iraq is a country that definitely has some type of "horn honking culture". Drivers use their car horns as a medium or a language to communicate with both fellow drivers on the road as well as pedestrians. A mix of long and short horns is used with each having a distinct meaning. The meanings range from road-related to others that have a more cultural aspect to them. Some of these include, for example, "watch out" which is expressed by both a short horn and a longer one, the longer one signals "anger" along with the meaning expressed. However, that same short horn changes in meaning according to context. If it is directed to someone walking down the street, it is a "greeting" that will be responded to with a hand wave or even another greeting but in words. As reported by a friend, her father honked a man walking down the street and that man immediately responded saying "salam wa rahmat Allah"3. Another meaning of the short horn is "thank you". Here, a typical example that is seen a lot in Iraq is when a driver waits for another driver to turn his car around on the road. As soon as the driver turns the car and clears the way, he will "beep" a "thanks" that will be answered with a hand wave, a head node or even another "beep" as if saying "not at all". In another context, when about to drive away leaving someone after a visit, a short horn means "bye". Other horn meanings include "need a taxi?", “where do I park my car?", "hey crazy", "hope in, I'll give you a ride", "here comes the bride" or even flirting as in "hello beautiful!".

\section{Discussion}

Sapir (1927) states that despite the difficulties of conscious analysis, "we respond to gestures with an extreme alertness, and one might almost say, in accordance with an elaborate and secret code that is written nowhere, known by none, and understood by all" (p. 556). Although some non-verbal behaviors are agreed on by researchers to be universally recognized especially facial expressions of happiness, sadness, anger, fear, disgust, and surprise, most other non-verbal behaviors show cultural differences whose lack of knowledge can cause miscommunication or confusion. Cultures include our beliefs and perceptions about the world; our sense of self, other, relationships, time, space, etc. (Mcdaniel, Samovar, \& Porter, 2012; Morreale et al., 2007; Ting-Toomy, 1999). It is transmitted implicitly, without awareness that one thinks of the behaviors enacted by his/her culture as the only way in which other humans should behave (Andersen, 2012; Burgoon et al., 2016; Gozalova et al., 2016; Matsumoto, 2006). Therefore, it is not surprising that non-verbal communication is heavily influenced by culture (De Vito, 2002).

Just like how kinesics, haptics, proxemics and other non-verbal channels or behaviors differ according to culture (Andersen, 2012; Burgoon \& Hobler, 2002;

"salam wa rahmat Allah" is a typical response to the greeting "salam alaikum" which are Arabic greetings that can be interpreted as "peace be upon you". 
Giri, 2009; Hall, 1990; Surkamp, 2014), so do car horns. Several factors may seem to have affected or helped in creating this unique cultural phenomena of horn honking communication. The first factor that is very tempting to blame is the chaotic or lawless streets. Although authors in Haiti, Jamaica, Thailand, India, Egypt and Iraq have reported that the streets there could be chaotic, lawless or crowded and driving in some of these countries is like a roller coaster ride, this, by no means, is the only factor. One reason is that we see the same horn honking communication in the organized streets of China, Italy, and Barbados. We even see that a country like Canada is establishing a language system out of car horns for effective communication between drivers. Another reason is that a second look at the same countries with the so called chaotic or lawless streets reveals that some of that horn honking communication occurs away from highways and main streets where the crowd is. It is in the neighborhoods where you hear all the "hellos", "byes", "thanks", "flirting", and other messages that are not road-related.

A second factor is the cultural dimension of context by which cultures are classified as high context (HC) and low context (LC). Context refers to the extent to which a communication is explicit and verbal or implicit and nonverbal. An HC culture is one where people rely more on the physical environment and other non-verbal cues rather than on the explicit or verbal aspect in order to get the meaning of a message. Whereas an LC culture is the opposite; information is explicitly stated through language rather than other non-verbal cues (Andersen, 2012; Hall, 1981; Nishimura, Nevgi, \& Tella, 2008). Hall's (1981) notion of HC/LC was suggested to help understand communication differences between cultures and it does, though partly, explain the phenomena of horn honking communication. Arabs, Asians, Mediterranean peoples and Indians are high-contest whereas North Americans are low-context (Hall, 1981; Hall \& Hall, 1990; Knuston, Komolsevin, Chatiketu, \& Smith, 2003; Nishimura et al., 2008). This means that six countries: Iraq, Egypt, China, Thailand, India and Italy, of the ten explored in this study are HC cultures and four; Haiti, Barbados, Jamaica and Canada, are LC cultures. Since people form HC cultures make more use of the environment and non-verbal cues, it is very logical that drivers in those six $\mathrm{HC}$ countries utilize the one thing that is at the touch of their hands to communicate with others around them especially when that horn can be heard farther than where their words could reach. The HC/ LC notion also explains why Americans do not use horn honking to communicate. Being from an LC culture, Americans not only depend more on the verbal code but also feel the need for detailed background information when communicating (Hall \& Hall, 1990). As to the four LC countries, it is important here to report what Hall (1981) has stated. According to him, even though cultures are classified as high or low, no culture exists exclusively at one end of the scale due to individual differences within the same culture. In addition, cultures are subject to change over time, i.e. from being an HC to LC and vice versa (Nishimura et al., 2008). So, let us first consider Canada. Even though it is classified as an LC culture, a non-verbal channel of communi- 
cation, i.e. a language using car horns is consciously established by the Canadian Motor Vehicles Advisory Commission to enable drivers to communicate more effectively. Kiselbach (2017) even argues that Canada is not an LC culture, but a hybrid of a 60/40 mix of both HC and LC. In Haiti, Jamaica, and Barbados, the communication through horn honking may not be as deliberate and conscious as that of Canada, but it can still be an example of individual differences or, maybe, a cultural change. Whether any of these four countries is merely showing individual differences or is changing from LC to HC culture is a question that can only be answered through close observation of different aspects and values of life over a long period of time.

Another possibly effective factor is social influence. Socializing and interacting with people is an essential part of human life that Burgoon and Hoobler (2002) describe our willingness to comply with others expectations for us as "striking", and that many of our actions can be accounted for by "a potent 'invisible' force"; i.e. the use of non-verbal cues. Just like in any other way, socializing and meeting others expectations for us can also manifest itself in horn honking. An example here is Barbados where Shattuck (2009) states:

A brief, musical sounding of a horn says, "Hello, I know you and I acknowledge you." If you don't respond to the first toot, they'll sound the call of the friendly horn again.

If you ignore them again, the honker takes it as a snub and you may as well forget getting invited to that person's Christmas party.

If you do respond, you re reinforcing social relationships and all is well (para. 9).

If horn honking is literally described as "reinforcing social relationships" or merely referred to as friendly, emotion expressive, and meaning expressive in the other countries, one can not overlook the fact that people's reaction/interaction with horns is another reason behind the formation and/or continuation of this horn honking phenomenon.

Whether it is because of the above mentioned factors or any others, communication using horn honking has obviously established itself as a cultural phenomenon. An evidence of this cultural phenomenon can be seen in cars by Peugeot and Ford who have adjusted their car horns to match the taste of the Chinese people. In fact, "cars don't tend to sell as well if they do not have the appropriate horn suiting the culture of honking on the roads" (Hong, 2014, para. 4). When honking is part of a culture, even if car makers do not adjust their car horns to suit that culture, people will do. In Egypt, "many Cairo drivers put in a louder horn when they get a new car" (Cox, 2012), and for some of those cultures like in India, the horn is described as probably more important than the breaks! (Rapoza, 2014).

Finally, having this cultural phenomenon of horn honking communication in many countries, and to be so established that some car makers take it into consideration while making their car horns calls for much more attention to it. I 
urge the need to further study this phenomenon and to add horn honking to other channels of non-verbal communication. It should be listed along with $\mathrm{ki}$ nesics, haptics, proxemics, etc. or at least be considered as a sub channel of the physical environment.

\section{Conclusion}

"Culture is communication and Communication is culture" (Hall, 1959: p. 218). Culture organizes our social lives, develops our understandings of the world and creates meanings for our behaviors. Yet, it is also a challenge because most of us are unaware that our beliefs and attitudes are so culture-specific until we are exposed to another culture. The biggest of these challenges is to be aware of the expectations and rules of non-verbal communication, for which there is no dictionary, in cultures outside our own. Therefore, to have healthy interactions with different cultures, it is important to understand how each channel of non-verbal communication differs from one culture to another (Andersen, 2012; Guirdham, 2005; Leeds-Hurwitz, 2009; Morreale et al., 2007; Tripathy, 2017).

Channels of non-verbal communication are many; kinesics, haptics, proxemics, and others mentioned earlier in the literature review have been identified and studied extensively by researchers across cultures. However, one important channel which is that of horn honking seems to be neglected or overlooked. The current paper shows that communication through horn honking has proved itself to be essential in the daily lives of people in many countries as part of their culture-as is hypothesized earlier by the researcher. With the increase of the number of people travelling for work, study or tourism, an understanding of the horn honking communication is very important because an "ignorance of this cultural nuance can lead to unwarranted stress, prangs, fights and injury when driving abroad" (Martin, 2017, para. 3). Thus, understanding non-verbal communication is more important than ever before. Although there seems no substitute for experience when it comes to gaining knowledge about other cultures, cultural differences and specifically those of non-verbal behavior can be understood and even appreciated through education. The best source for information on a culture is people from that culture (Andersen, 2012; Guirdham, 2005). So, to learn more about communication through horn honking, I invite for more research on the topic by researchers whose cultures "embrace the toot-toot".

\section{Limitations and Future Suggestions}

As original as this paper could be there still are a few limitations. One is the lack of academic data on the topic in addition to the lack of access I have to all the countries listed above in order to further test and validate people's accounts on the topic. However, having such a novel overview on horn honking as a nonverbal channel can serve as a starting point for future country-specific empirical studies on the topic which is what I will do next in my own country. 


\section{Acknowledgements}

I would like to express my deep gratitude to my wonderful friends for all the help and support they offered me. Thanks to Dr. Rana N. Aziz, Miss Admaa S. Rasheed, Dr. Shammaa' M. Aljanabi \& Dr. Alaa' M. Alhalbosy for proofreading and valuable comments. With deepest sadness, I have also to thank my dearest friend Mrs. Israa Kh. Al Falahi (may her soul rest in peace) who will not witness this paper publication; however, she left me with valuable comments and memories. Even more thanks are due to Mr. Ahmed I. Al Falahy for such a great help with the resources. A help without which, this paper would not have been as comprehensive as, I believe, it is.

\section{Conflicts of Interest}

The author declares no conflicts of interest regarding the publication of this paper.

\section{References}

(2016). Communication in the Real World: An Introduction to Communication Studies. University of Minnesota Libraries Publishing Edition [Adobe Digital Editions Version].

(2016, April 17). The Other Language of Jamaica: Taxi Horns. http://www.negrilhotels.com/blog/2016/04/the-other-language-of-jamaica-taxi-horns

Andersen, P. A. (2008). Nonverbal Communication: Forms and Functions (2nd ed.). Waveland Press.

Andersen, P. A. (2009). Proxemics. In S. W. Littlejohn, \& K. A. Foss (Eds.), Encyclopedia of Communication Theory (pp. 807-808). Sage Publication.

Andersen, P. A. (2012). The Basis of Cultural Differences in Nonverbal Communication. In L. A. Samovar, R. E. Porter, \& E. R. Mcdaniel (Eds.), Intercultural Communication: $A$ Reader (13th ed., pp. 293-313). Wadsworth, Cengage Learning.

Argyle, M. (2007). Bodily Communication (2nd ed.). Routledge.

Blinkhorn, R. (2013, May 30). The Four Tones of Chinese Car Horns. https://chinapersonified.com/the-four-tones-of-chinese-car-horns

Bruneau, T. (2009). Chronemics. In S. W. Littlejohn, \& K. A. Foss (Eds.), Encyclopedia of Communication Theory (pp. 96-101). Sage Publication.

Burgoon, J. K., \& Hoobler, G. D. (2002). Nonverbal Signals. In M. L. Knapp, \& J. A. Daly (Eds.), Handbook of Interpersonal Communication (3rd ed., pp. 240-299). Sage Publication.

Burgoon, J. K., Guerrero, L. K., \& Floyd, K. (2016). Nonverbal Communication. Routledge. https://doi.org/10.4324/9781315663425

Cheuk, N. (2014, August 13). Horn Honking in China. http://blogs.nottingham.ac.uk/chinesestudies/2014/08/13/horn-honking-in-china

Cox, P. (2012, September 18). A Note on: In Cairo, Cars Speak. https://patrickcox.wordpress.com/2012/09/18/in-cairo-cars-speak

De Vito, J. A. (1989). The Nonverbal Communication Workbook. Waveland Press.

De Vito, J. A. (2002). Human Communication: The Basic Course (9th ed.). Allyn \& Bacon.

Giri, V. N. (2009). Nonverbal Communication Theories. In S. W. Littlejohn, \& K. A. Foss 
(Eds.), Encyclopedia of Communication Theory (pp. 690-694). Sage Publication.

Gozalova, M. R., Gazilov, M. G. Kobeleva, O. V., Seredina M. I., \& Loseva E. S. (2016). Non-Verbal Communication in the Modern World. Mediterranean Journal of Social Sciences, 7, 553-558. https://doi.org/10.5901/mjss.2016.v7n4p553

Guirdham, M. (2005). Communicating across Cultures at Work (2nd ed.). Palgrave Macmillan.

Hall, E. T (1990). The Hidden Dimension. Anchor Books.

Hall, E. T. (1959). The Silent Language. Doubleday \& Company.

Hall, E. T. (1981). Beyond Culture. Anchor Books.

Hall, E. T., \& Hall, M. R. (1990). Understanding Cultural Differences. Intercultural Press.

Hargie, O. (2006). Skill in Practice: An Operational Model of Communicative Performance. In O. Hargie (Ed.), The Handbook of Communication Skills (3rd ed., pp. 37-70). Routledge.

Hersher, R. (Reporter) (2017, July 14). The Secret Car Horn Language of Port-au-Prince. https://www.npr.org/2017/07/14/537174782/the-secret-car-horn-language-of-port-auprince

Kamel, R. (2015, May 26). Honking: The Language of Love \& Rage on the Streets of Cairo. https://www.youtube.com/watch? $\mathrm{v}=\mathrm{Cr} 0 \mathrm{pPtNXkVQ}$

Kelly, P. (Reporter) (2015, October 7). Canada Rolls out Universal Car Horn Language. CBC Radio One.

https://www.cbc.ca/radio/thisisthat/canada-rolls-out-universal-car-horn-language-1.32 $\underline{59688}$

Kiselbach, A. (2017, July 10). What Makes Canada a High Context Culture? https://www.quora.com/What-makes-Canada-a-high-context-culture

Knapp, M. L., Hall, J. A., \& Horgan, T. G. (2014). Nonverbal Communication in Human Interaction (8th ed.). Wadsworth.

Knuston, T. J., Komolsevin, R., Chatiketu, P., \& Smith, V. R. (2003). A Cross-Cultural Comparison of Thai and US American Rhetorical Sensitivity: Implications for Intercultural Communication Effectiveness. International Journal of Intercultural Relations, 27, 63-78. https://doi.org/10.1016/S0147-1767(02)00060-3

Laitinen, M. (2011). Breaking the Rules of Communication: Verbal and Nonverbal Impoliteness in the American Hospital Drama House M.D. Unpublished Master's Thesis, University of Jyväskylä, Finland.

Leeds-Hurwitz, W. (2009). Social Construction of Reality. In S. W. Littlejohn, \& K. A. Foss (Eds.), Encyclopedia of Communication Theory (pp. 891-894). Sage Publication.

Littlejohn, W. S., \& Foss, K. A. (2008). Theories of Human Communication (9th ed.). Thomson Wadsworth.

Martin, J. (2017, April 15). The International Language of Honking. https://www.stuff.co.nz/travel/kiwi-traveller/91333037/the-international-language-of-h onking

Matsumoto, D. (2006). Culture and Nonverbal Behavior. In V. Manusov, \& M. L. Patterson (Eds.). The Sage Handbook of Nonverbal Communication (pp. 219-235). Sage. https://doi.org/10.4135/9781412976152.n12

Mcdaniel, E. R., Samovar, L. A., \& Porter, R. E. (2012). Using Intercultural Communication: The Building Blocks. In L. A. Samovar, R. E. Porter, \& E. R. Mcdaniel (Eds.), Intercultural Communication: A Reader (13th ed., pp. 4-19). Wadsworth, Cengage Learning. 
Miller, G. A. (1963). Language and Communication. McGraw-Hill Book.

Miller, N. (2015, October 12). Do You Speak Air Horns? http://learningindia.in/indian-horn-language

Morreale, S. P., Spitzberg, B. H., \& Barge, J. K. (2007). Human Communication: Motivation, Knowledge, and Skills (2nd ed.). Thomson Wadsworth.

Nishimura, S., Nevgi, A., \& Tella, S. (2008). Communication Style and Cultural Features in High/Low Context Communication Cultures: A Case Study of Finland, Japan and India. Subject-Didactic Symposium, Helsinki, 783-796.

Padula, A. (2009a). Kinesics. In S. W. Littlejohn, \& K. A. Foss (Eds.), Encyclopedia of Communication Theory (pp. 581-583). Sage Publication.

Padula, A. (2009b). Paralanguage. In S. W. Littlejohn, \& K. A. Foss (Eds.), Encyclopedia of Communication Theory (pp. 729-731). Sage Publication.

Rapoza, K. (2014, May 13). One Plausible Reason Why Indians Love Honking Horns. https://www.forbes.com/sites/kenrapoza/2014/05/13/one-plausible-reason-why-indian s-love-honking-horns/\#b496cf272adc

Runn, G. (2011, June 26). The Culture of Horn Honking. https://garyrunn.wordpress.com/2011/06/26/the-culture-of-horn-honking/

Sapir, E. (1927). The Unconscious Patterning of Behavior in Society. In D. G. Mandelbaum (Ed.), Selected Writings of Edward Sapir in Language, Culture, and Personality (pp. 544-559). University of California Press.

Scoop Team (2017, September 19). How Egyptians Utilize Car Horns as an Extra Means of Communication.

https://scoopempire.com/egyptians-utilize-car-horns-extra-means-communication

Shattuck, J. (2009, February 11). The Language of Horns in Barbados. http://planetbarbadosblog.com/2009/02/the-language-of-horns-in-barbados

Simon, J. (2012, September 18). In Cairo, Cars Speak. https://patrickcox.wordpress.com/2012/09/18/in-cairo-cars-speak

Stanciu, S. C., Eby, D. W., Molnar, M. J., Louis, R. M. St., \& Zanier, N. (2017). Interpersonal Communication and Issues for Autonomous Vehicles (ATLAS-2017-20). ATLAS Center, University of Michigan.

Surkamp, C. (2014). Non-Verbal Communication: Why We Need It in Foreign Language Teaching and How We Can Foster It with Drama Activities. Scenario, 2014, 12-27. https://doi.org/10.33178/scenario.8.2.3

Takada, M., Fukuda, Y., \& Iwamiya, S. I. (2008). Questionnaire Survey on Vehicle Horn Use. Journal of the Acoustical Society of America, 123, 3260. https://doi.org/10.1121/1.2933562

Ting-Toomey, S. (1999). Communicating across Cultures. New York: Guilford Press.

Tripathy, M. (2017). Understanding the Non Verbal Components of Cross Cultural Communication: A Perspective of Soft Skills. International Journal of Humanities and Social Science Invention, 6, 82-88.

Uyanne, M. C., \& Oti, O. J. (2012). The Linguistic Functions of Some Nonverbal Communication Features Operating as the Sub-Plane of Language Use. International Journal of Arts and Humanities, 1, 98-111. 


\section{Appendix}

Further Readings on Horn Honking:

Baron, R. A. (1976). The Reduction of Human Aggression: A Field Study of the Influence of Incompatible Reactions. Journal of Applied Social Psychology, 6, 260-274. https://doi.org/10.1111/j.1559-1816.1976.tb01330.x

Ben, J. (2002). Driver Aggression as a Function of Status Concurrence: An Analysis of Horn-Honking Responses. Institut für Soziologie, Universität Bern [Working Paper].

Doob A. N., \& Gross A. N. (1968). Status of Frustrator as an Inhibitor of Horn-Honking Responses. Journal of Social Psychology, 76, 213-218. https://doi.org/10.1080/00224545.1968.9933615

Dula, C. S., \& Geller, E. S. (2003). Risky, Aggressive, or Emotional Driving: Addressing the Need for Consistent Communication in Research. Journal of Safety Research, 34, 559-566. https://doi.org/10.1016/j.jsr.2003.03.004

Ellison, P. A., Govern, J. M., Petri, H. L., \& Figler, M. H. (1995). Anonymity and Aggressive Driving Behavior: A Field Study. Journal of Social Behavior and Personality, 10, 265-272.

Hennessy, D. A., \& Wiesenthal, D. L. (2002). Aggression, Violence, and Vengeance among Male and Female Drivers. Transportation Quarterly, 56, 65-75.

Kenrick, D. T., \& MacFarlane, S. W. (1986). Ambient Temperature and Horn Honking: A Field Study of the Heat/Aggression Relationship. Environment and Behavior, 18, 179191. https://doi.org/10.1177/0013916586182002

McGarva, A. R., \& Steiner, M. (2000). Provoked Driver Aggression and Status: A Field Study. Transportation Research Part F: Traffic Psychology and Behavior, 3, 167-179. https://doi.org/10.1016/S1369-8478(00)00023-1

Turner, C. W., Layton, J. F., \& Simons, L. S. (1975). Naturalistic Studies of Aggressive Behavior: Aggressive Stimuli, Victim Visibility, and Horn Honking. Journal of Personality and Social Psychology, 31, 1098-1107. https://doi.org/10.1037/h0076960 